\title{
CZ415, a Highly Selective mTOR Inhibitor Showing in Vivo Efficacy in a Collagen Induced Arthritis Model
}

Andrew D. Cansfield, ${ }^{\dagger, \perp}$ Tammy Ladduwahetty, ${ }^{\dagger, \S}$ Mihiro Sunose, ${ }^{\dagger, \|}$ Katie Ellard, ${ }^{\dagger, \#}$ Rosemary Lynch, ${ }^{\dagger, \%}$ Anthea L. Newton, ${ }^{\dagger,}$ Ann Lewis, ${ }^{\dagger, \Delta}$ Gavin Bennett, ${ }^{\dagger,}$ Nico Zinn, ${ }^{\dagger,}$ Douglas W. Thomson, Anne J. Rüger, ${ }^{\dagger} \bullet$ John T. Feutrill, ${ }^{\dagger, \approx}$ Oliver Rausch, ${ }^{\dagger, \times}$ Alan P. Watt, ${ }^{\dagger, \Delta}$ and Giovanna Bergamini ${ }^{*},+, \bullet$

${ }^{\dagger}$ Cellzome Ltd, Chesterford Research Park, Saffron Waldon, CB10 1XL, United Kingdom

${ }^{\ddagger}$ Cellzome AG, Meyerhofstraße 1, 69117 Heidelberg, Germany

Supporting Information

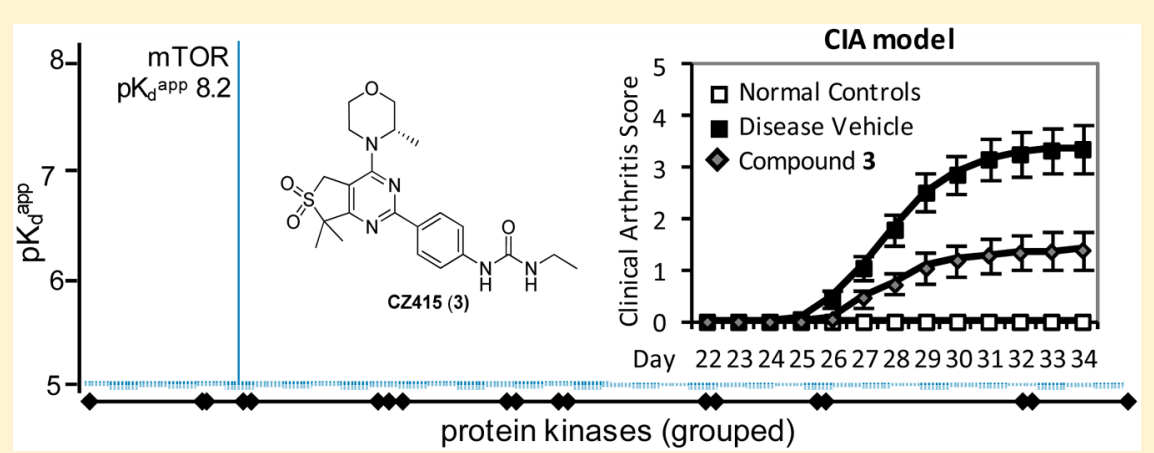

ABSTRACT: CZ415, a potent ATP-competitive mTOR inhibitor with unprecedented selectivity over any other kinase is described. In addition to a comprehensive characterization of its activities in vitro, in vitro ADME, and in vivo pharmacokinetic data are reported. The suitability of this inhibitor for studying in vivo mTOR biology is demonstrated in a mechanistic mouse model monitoring mTOR proximal downstream phosphorylation signaling. Furthermore, the compound reported here is the first ATP-competitive mTOR inhibitor described to show efficacy in a semitherapeutic collagen induced arthritis (CIA) mouse model.

KEYWORDS: mTOR, kinase inhibitor, inflammation, collagen induced arthritis model

$\mathrm{T}$ he mammalian target of rapamycin (mTOR/FRAP1) is a serine/threonine protein kinase, which belongs to a family of phosphoinositide 3-kinase-related kinases (PIKK), which also includes ATR, ATM, DNAPK, and SMG-1. FRAP1 is the catalytic subunit of two signaling complexes called mTORC1 and mTORC2, which play a central role in regulation of cell metabolism, proliferation, survival, and migration. ${ }^{1}$ It has been reported that mTOR is a key modulator in aging, dysregulated mTOR signaling can promote metabolic diseases and cancer and is often associated with inflammation. ${ }^{2,3}$ The broad interest in mTOR as a drug target is reflected by the growing number of mTOR inhibitors that have already been approved or are under clinical development. $^{4-9}$

To define further potential therapeutic uses and guide the development of safe and efficacious drugs it is crucial to fully understand the biological role of mTOR and the effects of its pharmacological inhibition. ${ }^{10}$ Ideally, target validation studies using small molecules should be conducted with multiple chemical probes to increase the confidence of target dependency of the observed phenotype and reduce the risk of misinterpretation of potential off-target effects. ${ }^{11}$ Quality criteria such as high selectivity, well characterized mode of action, and a favorable pharmacokinetic profile are a requirement to generate meaningful biological data and enable translation of in vitro findings to in vivo models. ${ }^{12}$

We report here a highly selective drug-like small molecule mTOR inhibitor from a novel chemical series, ${ }^{13}$ which shows efficacy in in vivo models.

The morpholine substituted pyrimidine core is a common structural motif that has been extensively explored for the development of ATP competitive mTOR inhibitors. ${ }^{14}$ In previous efforts on discovering mTOR inhibitors, we have also worked on this compound class and identified CZ830 (1) and CZ109 (2) as leads from two different chemical series (Figure 1). ${ }^{15,16}$ Both inhibitors showed moderate submicromolar affinity for mTOR and exhibited high selectivity of more than 100-fold over other lipid kinases from the same family, namely, phosphatidylinositide 3-kinases (PI3K) $\alpha / \beta / \gamma / \delta$ and DNAdependent protein kinase (DNAPK).

Received: April 8, 2016

Accepted: June 10, 2016

Published: June 10, 2016 


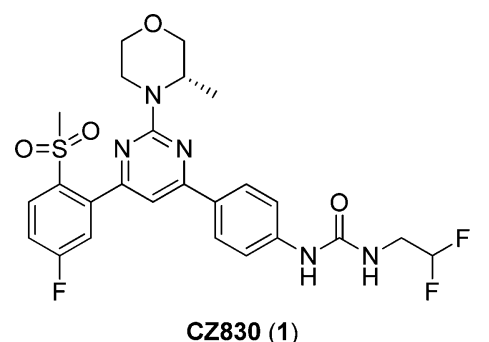

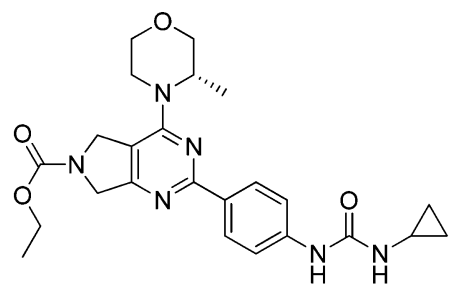

CZ109 (2)

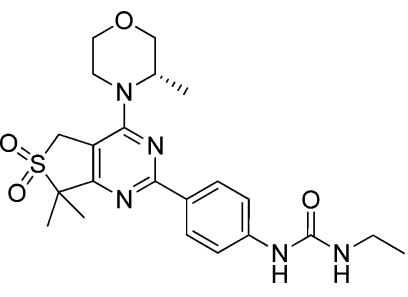

CZ415 (3)

Figure 1. mTOR inhibitors from different chemicals series. Starting from lead compounds $\mathbf{1}$ and $\mathbf{2}$, cyclic sulfone $\mathbf{3}$ was designed. ${ }^{13,15,16}$
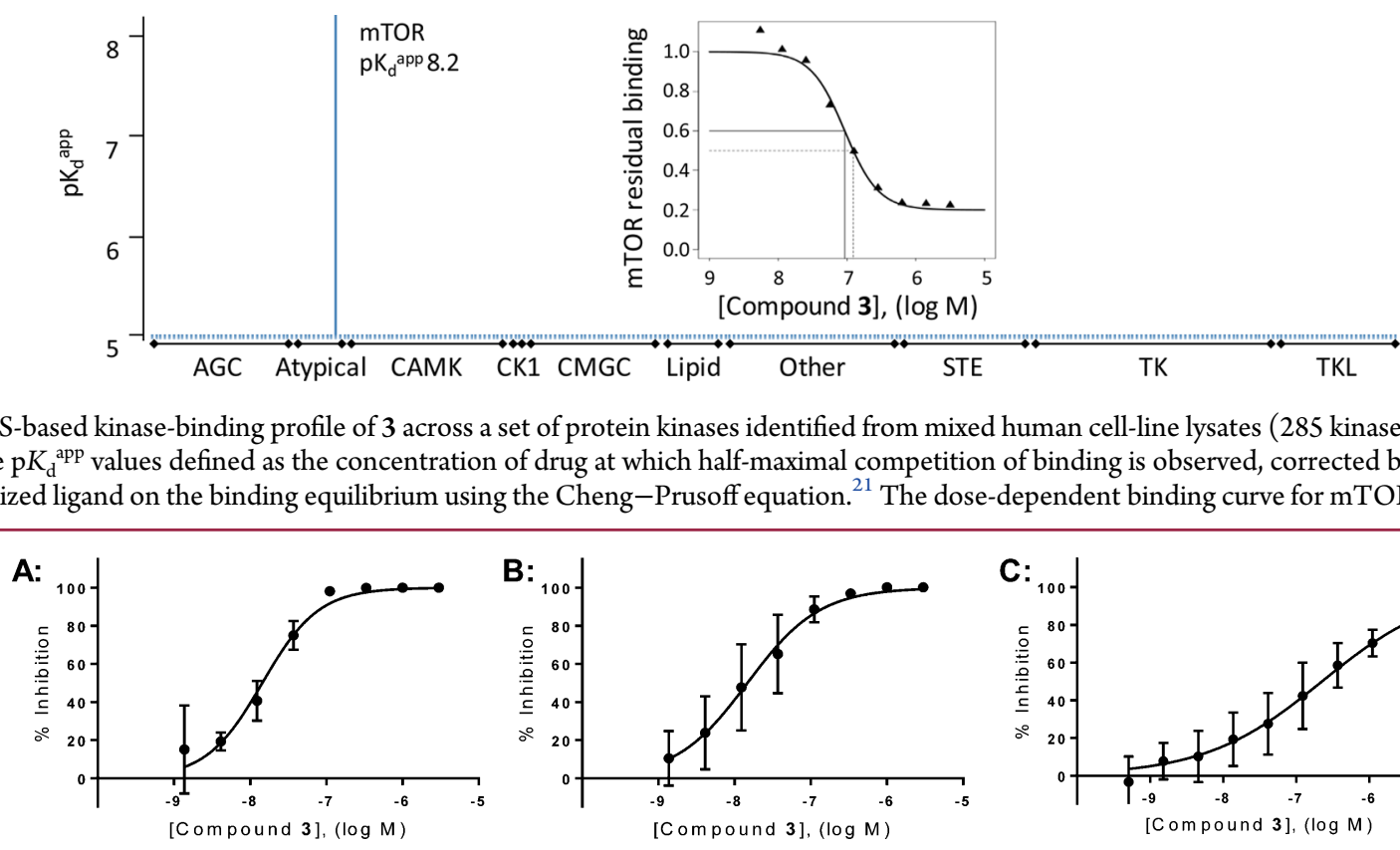

Figure 2. MS-based kinase-binding profile of 3 across a set of protein kinases identified from mixed human cell-line lysates (285 kinases identified). The bars indicate $\mathrm{p} K_{\mathrm{d}}^{\mathrm{app}}$ values defined as the concentration of drug at which half-maximal competition of binding is observed, corrected by the influence of the immobilized ligand on the binding equilibrium using the Cheng-Prusoff equation. ${ }^{21}$ The dose-dependent binding curve for mTOR is also depicted.
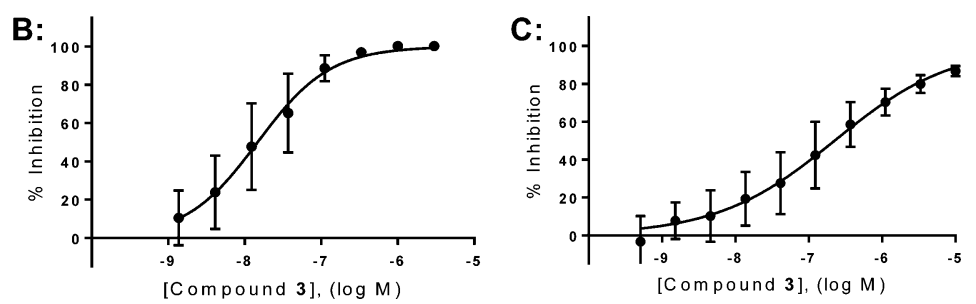

Figure 3. Activity of 3 in cellular assays: (A) Dose-dependent inhibition of S6RP phosphorylation in HEK293T after $2 \mathrm{~h}$ treatment of 3, normalized to total S6RP levels. $\mathrm{IC}_{50}=14.5 \mathrm{nM}(95 \%$ CI 11.5 to $18.3 \mathrm{nM}, n=4)$. (B) Dose-dependent inhibition of Akt phosphorylation in HEK293T after $2 \mathrm{~h}$ treatment of 3, normalized to total Akt levels. IC S $_{50}=14.8 \mathrm{nM}(95 \%$ CI 10.4 to $21.0 \mathrm{nM}, n=4)$. (C) Dose-dependent inhibition of IFN $\gamma$ release in stimulated human whole blood after $18 \mathrm{~h}$ treatment of 3 . $\mathrm{IC}_{50}=226 \mathrm{nM}(95 \%$ CI 169 to $303 \mathrm{nM}, n=4)$.

In order to discover more potent mTOR inhibitors, we combined both series, incorporating the sulfone moiety of compound 1 into the fused pyrimide core of 2 .

In addition to what was previously reported on cyclic sulfones, ${ }^{17}$ we broadly explored methyl-substitution on the five-membered ring. Compared to other five-membered sulfones, the introduction of a dimethyl-substituent was advantageous in terms of potency, selectivity, or solubility and gave a beneficial PK profile as compared to the six-membered sulfopyrimidines. The morpholine substituent was found to be crucial for maintaining high potency and selectivity, whereas multiple groups were tolerated on the urea moiety. This is consistent with reported mTOR crystal structure and models on close analogues showing morpholine making an important hinge binding interaction. ${ }^{14,17,18}$ Exploring this chemical series, our efforts culminated in the discovery of CZ415 (3), Figure 1. The synthesis of 3 and related cyclic sulfones has been previously reported $^{13}$ and is described in the Supporting Information.

The potency and selectivity of $\mathbf{3}$ was assessed using Cellzome's chemoproteomic platform. Competition binding experiments combined with a proteomic readout are a powerful tool to determine the selectivity of small molecules against a large portion of the proteome in a single experiment. ${ }^{19,20}$ With this approach, the compound's binding affinities were measured for approximately 285 protein kinases, including the family of lipid and atypical kinases. The apparent dissociation constant $\mathrm{p} K_{\mathrm{d}}^{\text {app }}$ for 3 against $\mathrm{mTOR}$ was found to be 8.2, while any other kinase identified in the experiments, including PI3K family members, found to be frequent off-targets of other mTOR inhibitors, did not show any affinity within 1000-fold. The remarkable selectivity of 3 is depicted in Figure 2 (detailed list of proteins is provided in Supporting Information).

To verify that binding of 3 to mTOR results in inhibition of both mTORC1- and mTORC2-dependent signaling in the cellular context, 3 was tested in a cellular mechanistic assay. Inhibition of mTORC1 and mTORC2 protein complex activity was assessed by monitoring the phosphorylation of downstream targets, S6 Ribosomal Protein (S6RP, downstream of mTORC1) and Protein Kinase B (=Akt, mTORC2 substrate). Phosphorylation levels for both proteins, pS6RP (S240/244) and pAkt (S473), were assessed in dose response format from HEK293T cells after treatment with 3. As depicted in Figure 3, inhibition of phosphorylation for both downstream targets resulted in 14.5 $\mathrm{nM} \mathrm{IC} \mathrm{I}_{50}$ for $\mathrm{pS6RP}$ and $14.8 \mathrm{nM}$ for pAKT (Western Blot analysis and Caspase $3 / 7$ activity assay are reported in the Supporting Information). Retaining high potency against mTOR in the cellular system proves functional inhibition of the target and indicates very good cell permeability $\left(K_{\mathrm{d}}{ }^{\text {app }}=6.9 \mathrm{nM}\right.$ 
determined by chemoproteomic binding assay from cellular lysate, see above). Furthermore, interferon gamma (IFN $\gamma$ ) release in whole blood was used to test mTOR inhibition in primary cells. Treatment of whole blood with monoclonal antibodies binding to cluster of differentiation 3 and $28(\alpha \mathrm{CD} 3 /$ $\alpha \mathrm{CD} 28)$ mimics antigen receptor signaling and activates proliferation of T-lymphocytes. Costimulation with Interleukin 2 (IL-2) then induces interferon gamma gene (IFNG) expression and IFN $\gamma$ is released. ${ }^{22}$ The immunosuppressive effect of 3 was measured by detecting secreted IFN $\gamma$ after $18 \mathrm{~h}$ in stimulated human whole blood, and the resulting $\mathrm{IC}_{50}$ was 226 nM (Figure 3).

We have further investigated the properties of 3 in dedicated in vitro assays for early drug safety prediction. The cytochromes P450 (CYPs) are a family of enzymes that play a major role in drug metabolism, and interaction with them is related to potential drug-drug interactions and adverse drug reactions. In human microsomes, no inhibition of the main P450 isoforms CYP1A, CYP2C8, CYP2C9, CYP2C19, CYP2D6, and CYP3A4 was observed within a 1000 -fold window of mTOR affinity. Further tests for cytochrome CYP3A4 also showed no induction at $10 \mu \mathrm{M}$ and no time-dependent inhibition (TDI) at a concentration as high as $50 \mu \mathrm{M}$.

As a predictor for cardiotoxicity, the activity of 3 against the human cardiac ion channel hERG was assessed in a whole-cell patch-clamp assay in HEK293 cells, resulting in an $\mathrm{IC}_{50}$ of $48 \mu \mathrm{M}$. We were further pleased that 3 showed no genotoxic potential. It was neither mutagenic in a bacterial mutation assay (Ames test) nor did it show genotoxicity in the mouse lymphoma assay (MLA), in either the presence or absence of rat-liver S9 mix. Given the data reported above for 3 , there were no safety related liabilities predicted for this compound. Next to potency/ selectivity assessment and early safety prediction, physicochemical properties are important for the successful development of drugs as well as for high quality probes, which can be used in vivo. $^{23,24}$ Compound 3 has a moderate molecular weight (MW 460) and polar surface area (PSA 114), both in the desirable chemical space for bioavailable drugs. Despite a relatively high distribution coefficient $\left(\log \mathrm{D}_{\mathrm{pH7.4}} 4.31\right), 3$ showed good kinetic solubility (CLND $149.5 \mu \mathrm{M}$ ) as well as solubility in biorelevant media, which is important for oral administration (FaSSIF 11.1 $\mu \mathrm{g} / \mathrm{mL}$, FeSSIF $60.1 \mu \mathrm{g} / \mathrm{mL}$ ). The permeability measured in a Caco-2 assay, predictive for in vivo absorption of drugs across the gut wall, was moderate (Papp (A-B) $0.47 \mathrm{~nm} / \mathrm{s}$ and Papp (B-A) $1.02 \mathrm{~nm} / \mathrm{s}$ ). A table summarizing physicochemical properties of 3 is provided in the Supporting Information.

The pharmacokinetic (DMPK) properties of a compound determine its ability to act over time on the molecular target. A low rate of drug metabolism is desirable for long acting compounds to maintain sufficient compound levels in plasma. As in vitro determination of the metabolic stability can help predicting in vivo $\mathrm{PK}$, stability of $\mathbf{3}$ was assessed in microsomes and hepatocytes from different species. Low to moderate intrinsic clearance was measured, resulting in a calculated $\mathrm{Cl}_{\text {int }}$ $<0.6 /<1.1 / 1.5 \mu \mathrm{L} / \mathrm{min} / \mathrm{g}$ liver in microsomes and $\mathrm{Cl}_{\text {int }}$ n.d./ $<0.8 / \leq 0.5 \mu \mathrm{L} / \mathrm{min} / \mathrm{g}$ liver in hepatocytes (rat/dog/human). In addition to the metabolic stability, measurement of plasma protein binding (PPB) enables estimation of the free fraction of compound in the bloodstream. PPB of 3 in rat, mouse, and human plasma was determined to be $69 / 89 / 81 \%(\mathrm{r} / \mathrm{m} / \mathrm{h})$, indicating a sufficient free fraction of the compound being available for binding to the target.

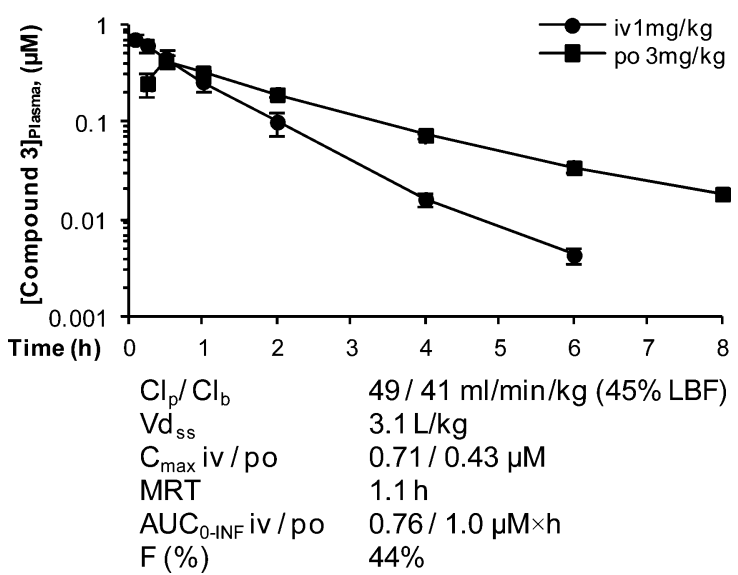

Figure 4. Time-dependent plasma concentration of 3 after intravenous bolus (iv, circle) and oral solution (po, square) administration to rats. Rats were dosed at $1 \mathrm{mg} / \mathrm{kg}(\mathrm{iv}, n=3)$ or $3 \mathrm{mg} / \mathrm{kg}(\mathrm{po}, n=3)$. Vehicle: $5 \%$ DMSO/95\% (10\% Kleptose).

For full characterization of 3 and to enable improved dose predictions, the pharmacokinetic (PK) profile was assessed in rat. PK and oral bioavailability were determined after $1 \mathrm{mg} / \mathrm{kg}$ intravenous (iv) bolus and $3 \mathrm{mg} / \mathrm{kg}$ oral (po) administration (Figure 4). The observed plasma clearance, corresponding to $45 \%$ liver blood flow, suggested that sufficient levels of free compound were circulating in the animal over time. The oral uptake was rapid with a $T_{\max }$ of $0.5 \mathrm{~h}$ and bioavailability $F=44 \%$ indicated very good absorption from the gut. The plasma concentration peaked at $0.43 \mu \mathrm{M}$, which was above the $\mathrm{IC}_{50}$ determined in cellular assays for 3 .

To demonstrate the efficacy of 3 in vivo, modulation of mTOR proximal downstream signaling has been monitored in a mechanistic mouse model. In vivo treatment with anti-CD3 antibody specifically stimulates $\mathrm{T}$ cells upon binding to the CD3 receptor and subsequent downstream activation of the PI3K/ mTOR signaling pathway. ${ }^{25}$ To determine the effects of 3 on its pharmacological target, dose-dependent changes in phosphorylation levels of S6 Ribosomal Protein and Akt, both downstream targets of mTOR, were assessed. The inhibitor was administered orally at 1,3 , and $10 \mathrm{mg} / \mathrm{kg}$ to mice $1 \mathrm{~h}$ before anti-CD3 stimulus. Fifteen min after stimulation, spleens were dissected and analyzed for pS6RP and pAKT levels. A dose related significant inhibition of phosphorylation of both S6RP and Akt was observed after compound administration (Figure 5A,C). In particular, 1 and $3 \mathrm{mg} / \mathrm{kg} 3$ could fully inhibit S6RP phosphorylation induced by anti-CD3 stimulation, and $10 \mathrm{mg} /$ $\mathrm{kg}$ additionally decreased the constitutive phosphorylation levels as measured in the control group. While phosphorylation of Akt was not increased upon anti-CD3 stimulation (Figure 5C), 3, already at the lowest dose of $1 \mathrm{mg} / \mathrm{kg}$, significantly reduced pAkt constitutive levels, as measured in the control group. The PK/PD relationship was determined following measurement of compound concentration in blood, and the exposure-response correlation is depicted in Figure 5B,D. An $\mathrm{EC}_{50}$ of $0.22 \mu \mathrm{M}$ was measured for $\mathrm{pS} 6 \mathrm{RP}$ and $0.055 \mu \mathrm{M}$ for pAkt, which correlate well with the nanomolar potency of $\mathbf{3}$ in the cell based assays. These results showed 3 to be a potent mTOR inhibitor, which retained its activity in vivo.

In vivo efficacy of $\mathbf{3}$ was then assessed in an inflammatory context. In the collagen induced arthritis (CIA) model, mice reliably develop polyarthritis when immunized against bovine type II collagen, and this model can be utilized to monitor anti- 
A:

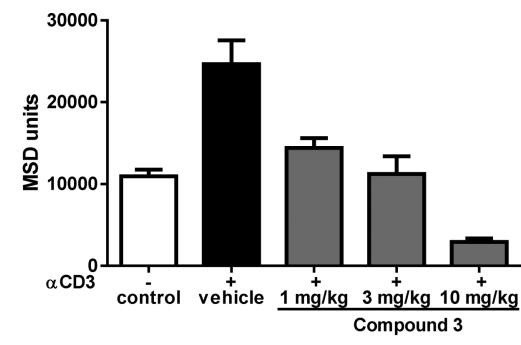

C:

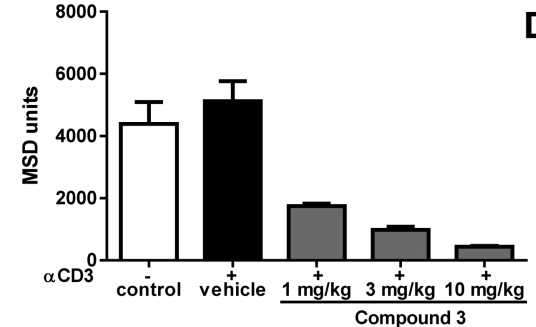

B:

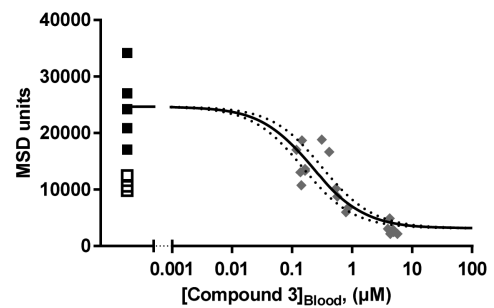

D:

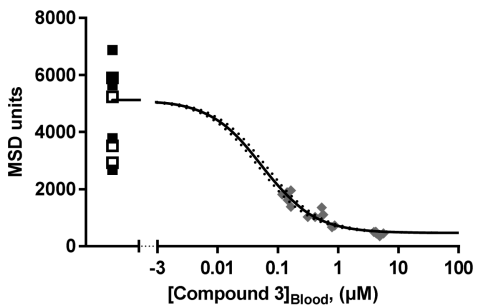

Figure 5. Compound 3 in anti-CD3 mouse model. (A) pS6RP levels (normalized to total S6RP) measured in spleens of compound treated as compared to disease vehicle group ( $p<0.01$ for $1 \mathrm{mg} / \mathrm{kg}$ of $3 ; p<0.001$ for 3 and $10 \mathrm{mg} / \mathrm{kg}$ of 3; one outlier removed in normal control and disease vehicle group). (B) Exposure response fit: pS6RP levels at terminal exposure. $\mathrm{EC}_{50} 0.22 \mu \mathrm{M}(95 \% \mathrm{CI} 0.15$ to $0.32 \mu \mathrm{M})$. (C) pAkt levels (normalized to total Akt) measured in spleens of compound treated as compared to disease vehicle group ( $p<0.001$ for 1,3, and $10 \mathrm{mg} / \mathrm{kg}$ of 3). (D) Exposure response fit: pAkt levels at terminal exposure. $\mathrm{EC}_{50} 0.055 \mu \mathrm{M}(95 \% \mathrm{CI} 0.048$ to $0.065 \mu \mathrm{M})$. Legend: White, normal controls $(n=4)$. Black, anti-CD3 vehicle 5\%DMSO/ $95 \%$ (10\% kleptose) $(n=6)$. Gray, anti-CD3/3 $(1,3$, or $10 \mathrm{mg} / \mathrm{kg}$, of $3 \mathrm{PO})(n=6)$.
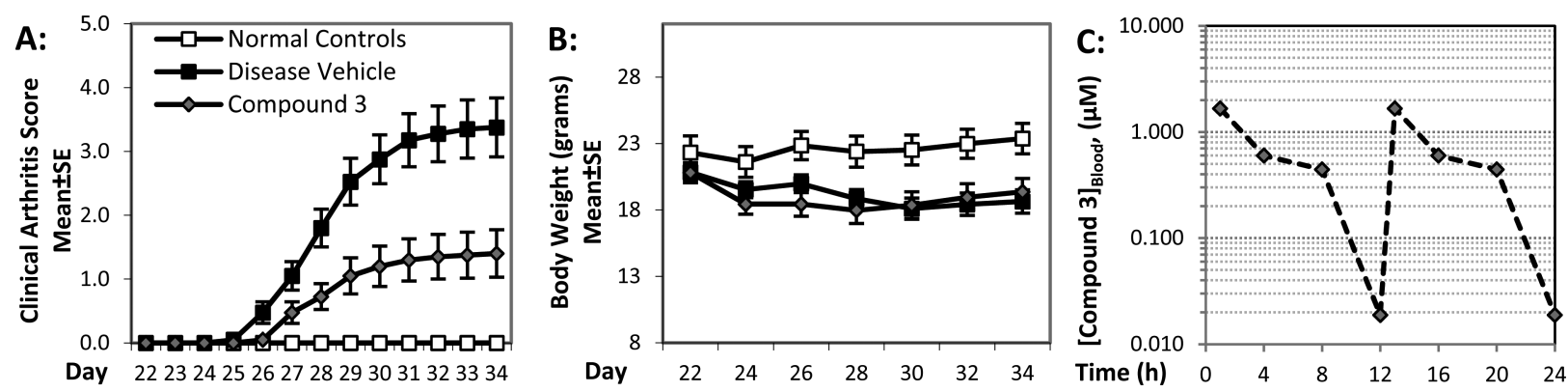

Figure 6. Compound 3 in a mouse CIA model. (A) Clinical arthritis score, all paws (Scored 0-5). Normal controls (white squares): significance ( $p \leq$ 0.05 ) from disease vehicle group (black squares) observed at day 27 through day 34 . Compound 3 at $10 \mathrm{mg} / \mathrm{kg}$, bid (gray dots): significant reduction as compared to disease vehicle group at day 33-34 $(p \leq 0.05)$. (B) Body weight over time. Significant difference of normal controls at day 26 through day 34 as compared to disease vehicle group, and of $10 \mathrm{mg} / \mathrm{kg} 3$ at day 26 ( $p \leq 0.05$ to disease vehicle). (C) Drug levels of 3 in blood on study day 31 . Exposure: AUC $14 \mu \mathrm{M} \times \mathrm{h}, C_{\max } 1.7 \mu \mathrm{M}$. Legend: Normal controls $(n=4)$, disease vehicle (5\%DMSO/95\% (10\% kleptose), $\left.n=10\right)$, Compound 3 (10 $\mathrm{mg} / \mathrm{kg}, \mathrm{PO}, n=10)$.

inflammatory effects of the tested compounds. It has been shown that treatment with Rapalogs can inhibit the clinical severity of arthritis in mice, ${ }^{26-28}$ but the effect of ATP-competitive mTOR inhibitors has not previously been reported. A so-called semiestablished study design was utilized for testing 3 at 10 $\mathrm{mg} / \mathrm{kg}$ twice daily. Mice were challenged with two injections of collagen, the first at day 0 and a boost injection at day 21 . Administration of 3 started at day 22, immediately before the onset of the disease, and continued until day 34 at termination of the study. The development of arthritis, which reached $100 \%$ disease incidence in the vehicle group, was determined by evaluation of clinical arthritis scores (from 0 to 5) that were measured by inspection of the paws for erythema and swelling. The daily clinical arthritis scores of the treated group differed from disease control group over time with significant reductions $(p<0.05)$ at day 33-34 (Figure 6A). Clinical arthritis scores expressed as area under the curve (AUC) were reduced in the group treated with 3 by $59 \%$ as compared to the disease vehicle group (data not shown). No significant difference in body weight loss was observed compared to vehicle-treated, disease-induced mice at end of the study (Figure 6B). Measurement of compound concentrations in blood, determined on day 31 , indicated that up to $8 \mathrm{~h}$ after dosing the levels of circulating 3 were above $\mathrm{EC}_{50}$ as determined both in vitro in the whole blood assay and in vivo in the $\mathrm{PK} / \mathrm{PD}$ mouse model (Figure 6C). Unlike many antiinflammatory molecules that require prophylactic dosing in the CIA, this data demonstrates that $\mathbf{3}$ is active in a situation more akin to human disease.

We have presented here a highly potent mTOR inhibitor CZ415 (3) with exquisite selectivity over other lipid and protein kinases. It has a defined mechanism of action, which was demonstrated in mechanistic and phenotypic cell based assays, including a whole blood assay. In addition to favorable physicochemical properties, early in vitro safety assessment did not exhibit any liabilities. Pharmacokinetic properties of moderate clearance and good oral bioavailability showed suitability of 3 for progression to in vivo studies. In an antiCD3 mouse model 3 efficiently inhibited mTOR downstream signaling and, in a CIA mouse model, showed significant antiinflammatory effects. With its extraordinary selectivity, drug-like properties and proven efficacy in vivo, 3 represents an ideal 
molecule for the pharmacological investigation of mTOR pathophysiological role in vivo.

\section{ASSOCIATED CONTENT}

\section{S Supporting Information}

The Supporting Information is available free of charge on the ACS Publications website at DOI: 10.1021/acsmedchemlett.6b00149.

Synthesis, analytical data, and physicochemical properties for 3, protocols for selectivity profiling and cellular assays including Western blot, and animal studies (PDF)

List of proteins identified in kinase-binding profiling (PDF)

\section{AUTHOR INFORMATION}

\section{Corresponding Author}

*E-mail: giovanna.2.bergamini@gsk.com.

\section{Present Addresses}

${ }^{\perp}$ Heptares Therapeutics, BioPark, Broadwater Road, Welwyn Garden City, Hertfordshire, AL7 3AX, U.K.

${ }^{\S}$ Charles River Laboratories, Early Discovery, Harlow, Essex, CM 19 5TR, U.K.

"Sygnature Discovery Ltd., BioCity, Pennyfoot Street, Nottingham, NG1 1GF, U.K.

\# Joyce Frankland Academy, Newport, Saffron Walden, Essex, CB11 3TR, U.K.

${ }^{\%}$ Aqdot Ltd., Iconix Park, London Road, Cambridge, CB22 3EG, U.K.

LGC Ltd., Newmarket Road, Fordham, Cambridgeshire, CB7 SWW, U.K.

${ }^{\Delta}$ Xenovium, Chesterford Research Park, Saffron Waldon, CB10 1XL, U.K.

Bicycle Therapeutics Ltd., Babraham Research Campus, Cambridge, CB22 3AT, U.K.

$\approx$ SYNthesis med chem, 399 Royal Parade, Parkville, VIC 3052, Australia.

${ }^{\times}$National Institute for Health Research, Translational Research Partnerships, 80 London Rd, London, SE1 6LH, U.K.

- Cellzome GmbH, a GSK company, Meyerhofstraße 1, 69117 Heidelberg, Germany.

\section{Author Contributions}

G.Ber. and A.J.R. wrote the manuscript, T.L. and M.S. designed and participated in the execution of the work, A.D.C., R.L, K.E., and J.F. participated in the chemical design and synthesis, A.L.N. designed and performed the cellular assays, A.L. supervised and analyzed the DMPK studies, G.Ben. supervised and analyzed the animal model studies, D.W.T. and N.Z. supervised and analyzed the selectivity profiling work, A.P.W. and O.R. contributed to the design of the studies, and G.Ber. designed and supervised the work reported. All authors have given approval to the final version of the manuscript.

\section{Notes}

The authors declare no competing financial interest.

\section{ACKNOWLEDGMENTS}

We thank Cellzome chemistry, biology, pharmacology, biochemistry, informatics, and mass spectrometry departments, the leadership team and the whole mTOR program team for support and advice. The human biological samples were sourced ethically and their research use was in accord with the terms of the informed consents. All animal studies were ethically reviewed and carried out in accordance with European legislation and guidelines for animal welfare.

\section{ABBREVIATIONS}

Akt, Protein Kinase B; ATM, ataxia telangiectasia mutated kinase; ATR, ataxia telangiectasia and Rad3-related protein; $\alpha \mathrm{CD} 3 / \alpha \mathrm{CD} 28$, monoclonal antibodies binding to cluster of differentiation 3/28; CIA, collagen induced arthritis; DNAPK, DNA-dependent protein kinase; IFN $\gamma$, interferon gamma; IFNG, interferon gamma gene; IL-2, Interleukin 2; $K_{d}^{\text {app }}$, apparent dissociation constant; mTOR, mammalian target of rapamycin; PI3K, phosphatidylinositide 3-kinases; PIKK, family of phosphoinositide 3-kinase-related kinases; $\mathrm{PK} / \mathrm{PD}$, pharmacokinetic/pharmacodynamic; SMG-1, nonsense mediated mRNA decay associated PI3K related kinase; S6RP, S6 Ribosomal Protein

\section{REFERENCES}

(1) Laplante, M.; Sabatini, D. M. mTOR signaling at a glance. J. Cell Sci. 2009, 122, 3589-3594.

(2) Zoncu, R.; Efeyan, A.; Sabatini, D. M. mTOR: from growth signal integration to cancer, diabetes and ageing. Nat. Rev. Mol. Cell Biol. 2011, $12,21-35$.

(3) Johnson, S. C.; Rabinovitch, P. S.; Kaeberlein, M. mTOR is a key modulator of ageing and age-related disease. Nature 2013, 493, 338345.

(4) Benjamin, D.; Colombi, M.; Moroni, C.; Hall, M. N. Rapamycin passes the torch: a new generation of mTOR inhibitors. Nat. Rev. Drug Discovery 2011, 10, 868-880.

(5) Sun, S.-Y. mTOR kinase inhibitors as potential cancer therapeutic drugs. Cancer Lett. 2013, 340, 1-8.

(6) Jessen, K.; Wang, S.; Kessler, L.; Guo, X.; Kucharski, J.; Staunton, J.; Lan, L.; Elia, M.; Stewart, J.; Brown, J.; Li, L.; Chan, K.; Martin, M.; Ren, P.; Rommel, C.; Liu, Y. INK128 is a potent and selective TORC1/2 inhibitor with broad oral antitumor activity. Mol. Cancer Ther. 2009, 8, B148.

(7) Chresta, C.; Davies, B. R.; Hickson, I. AZD8055 Is a Potent, Selective, and Orally Bioavailable ATP-Competitive Mammalian Target of Rapamycin Kinase Inhibitor with In vitro and In vivo Antitumor Activity. Cancer Res. 2010, 70, 288-298.

(8) Mortensen, D. S.; Fultz, K. E.; Xu, S.; Xu, W.; Packard, G.; Khambatta, G.; Gamez, J. C.; Leisten, J.; Zhao, J.; Apuy, J.; Ghoreishi, K.; Hickman, M.; Narla, R. K.; Bissonette, R.; Richardson, S.; Peng, S. X.; Perrin-Ninkovic, S.; Tran, T.; Shi, T.; Yang, W. Q.; Tong, Z.; Cathers, B. E.; Moghaddam, M. F.; Canan, S. S.; Worland, P.; Sankar, S.; Raymon, H. K. CC-223, a Potent and Selective Inhibitor of mTOR Kinase: In Vitro and In Vivo Characterization. Mol. Cancer Ther. 2015, 14, 12951305.

(9) Liu, Q.; Kirubakaran, S.; Hur, W.; Niepel, M.; Westover, K.; Thoreen, C. C.; Wang, J.; Ni, J.; Patricelli, M. P.; Vogel, K.; Riddle, S.; Waller, D. L.; Traynor, R.; Sanda, T.; Zhao, Z.; Kang, S. A.; Zhao, J.; Look, A. T.; Sorger, P. K.; Sabatini, D. M.; Gray, N. S. Kinome-wide Selectivity Profiling of ATP-competitive Mammalian Target of Rapamycin (mTOR) Inhibitors and Characterization of Their Binding Kinetics. J. Biol. Chem. 2012, 287, 9742-9752.

(10) Bunnage, M. E.; Gilbert, A. M.; Jones, L. H.; Hett, E. C. Nat. Chem. Biol. 2015, 11, 368-372.

(11) Bunnage, M. E.; Chekler, E. L.; Jones, L. H. Target validation using chemical probes. Nat. Chem. Biol. 2013, 9, 195-199.

(12) Arrowsmith, C. H.; Audia, J. E.; Austin, C.; Baell, J.; Bennett, J.; Blagg, J.; Bountra, C.; Brennan, P. E.; Brown, P. J.; Bunnage, M. E.; Buser-Doepner, C.; Campbell, R. M.; Carter, A. J.; Cohen, P.; Copeland, R. A.; Cravatt, B.; Dahlin, J. L.; Dhanak, D.; Edwards, A. M.; Frye, S. V.; Gray, N.; Grimshaw, C. E.; Hepworth, D.; Howe, T.; Huber, K. V.; Jin, J.; Knapp, S.; Kotz, J. D.; Kruger, R. G.; Lowe, D.; Mader, M. M.; Marsden, B.; Mueller-Fahrnow, A.; Muller, S.; O'Hagan, R. C.; Overington, J. P.; Owen, D. R.; Rosenberg, S. H.; Roth, B.; Ross, R.; 
Schapira, M.; Schreiber, S. L.; Shoichet, B.; Sundstrom, M.; SupertiFurga, G.; Taunton, J.; Toledo-Sherman, L.; Walpole, C.; Walters, M. A.; Willson, T. M.; Workman, P.; Young, R. N.; Zuercher, W.J. The promise and peril of chemical probes. Nat. Chem. Biol. 2015, 11, 536-541.

(13) Lynch, R.; Cansfield, A. D.; Hardy, D. P.; Feutrill, J. T.; Adrego, R.; Ellard, K.; Ladduwahetty, T. Morpholino substituted bicyclic pyrimidine urea or carbamate derivatives as mTOR inhibitors. PCT Int. Appl. WO 2013050508 A1, 2013.

(14) Andrs, M.; Korabecny, J.; Jun, D.; Hodny, Z.; Bartek, J.; Kuca, K. Phosphatidylinositol 3-Kinase (PI3K) and Phosphatidylinositol 3Kinase-Related Kinase (PIKK) Inhibitors: Importance of the Morpholine Ring. J. Med. Chem. 2015, 58, 41-71.

(15) Lynch, R.; Cansfield, A.; Niblock, H. S.; Hardy, D.; Scanlon, J. E.; Adrego, R.; Ramsden, N. Pyrimidine derivatives as mTOR inhibitors. PCT Int. Appl. WO 2010103094 Al, 2010.

(16) Lynch, R.; Cansfield, A. D.; Niblock, H. S.; Hardy, D. P.; Taylor, J. Morpholino substituted urea derivatives as mTOR inhibitors. PCT Int. Appl. WO 2011107585 A1, 2011.

(17) Liu, K. K.-C.; Bailey, S.; Dinh, D. M.; Lam, H.; Li, C.; Wells, P. A.; Yin, M.-J.; Zou, A. Conformationally-restricted cyclic sulfones as potent and selective mTOR kinase inhibitors. Bioorg. Med. Chem. Lett. 2012, 22, 5114-5117.

(18) Yang, H.; Rudge, D. G.; Koos, J. D.; Vaidialingam, B.; Yang, H. J.; Pavletich, N. P. mTOR kinase structure, mechanism and regulation. Nature 2013, 497, 217-224.

(19) Bantscheff, M.; Eberhard, D.; Abraham, Y.; Bastuck, S.; Boesche, M.; Hobson, S.; Mathieson, T.; Perrin, J.; Raida, M.; Rau, C.; Reader, V.; Sweetman, G.; Bauer, A.; Bouwmeester, T.; Hopf, C.; Kruse, U.; Neubauer, G.; Ramsden, N.; Rick, J.; Kuster, B.; Drewes, G. Quantitative chemical proteomics reveals mechanisms of action of clinical ABL kinase inhibitors. Nat. Biotechnol. 2007, 25, 1035-1044.

(20) Bergamini, G.; Bell, K.; Shimamura, S.; Werner, T.; Cansfield, A.; Muller, K.; Perrin, J.; Rau, C.; Ellard, K.; Hopf, C.; Doce, C.; Leggate, D.; Mangano, R.; Mathieson, T.; O’Mahony, A.; Plavec, I.; Rharbaoui, F.; Reinhard, F.; Savitski, M. M.; Ramsden, N.; Hirsch, E.; Drewes, G.; Rausch, O.; Bantscheff, M.; Neubauer, G. A selective inhibitor reveals PI3K $\gamma$ dependence of TH17 cell differentiation. Nat. Chem. Biol. 2012, $8,576-582$.

(21) Sharma, K.; Weber, C.; Bairlein, M.; Greff, Z.; Kéri, G.; Cox, J.; Olsen, J. V.; Daub, H. Proteomics strategy for quantitative protein interaction profiling in cell extracts. Nat. Methods 2009, 6, 741-744.

(22) Ghosh, P.; Buchholz, M. A.; Yano, S.; Taub, D.; Longo, D. L. Effect of rapamycin on the cyclosporin A-resistant CD28-mediated costimulatory pathway. Blood 2002, 99, 4517-4524.

(23) Lipinski, C. A. Lead- and drug-like compounds: the rule-of-five revolution. Drug Discovery Today: Technol. 2004, 1, 337-341.

(24) Abad-Zapatero, C. Ligand efficiency indices for effective drug discovery. Expert Opin. Drug Discovery 2007, 2, 469-488.

(25) Delgoffe, G. M.; Pollizzi, K. N.; Waickman, A. T.; Heikamp, E.; Meyers, D. J.; Horton, M. R.; Xiao, B.; Worley, P. F.; Powell, J. D. The kinase $\mathrm{mTOR}$ regulates the differentiation of helper $\mathrm{T}$ cells through the selective activation of signaling by mTORC1 and mTORC2. Nat. Immunol. 2011, 12, 295-303.

(26) Carlson, R. P.; Baeder, W. L.; Caccese, R. G.; Warner, L. M.; Sehgal, S. N. Effects of orally administered rapamycin in animal models of arthritis and other autoimmune diseases. Ann. N. Y. Acad. Sci. 1993, $685,86-113$.

(27) Cejka, D.; Hayer, S.; Niederreiter, B.; Sieghart, W.; Fuereder, T.; Zwerina, J.; Schett, G. Mammalian target of rapamycin signaling is crucial for joint destruction in experimental arthritis and is activated in osteoclasts from patients with rheumatoid arthritis. Arthritis Rheum. 2010, 62, 2294-2302.

(28) Lin, J. T.; Stein, E. A.; Wong, M. T.; Kalpathy, K. J.; Su, L. L.; Utz, P. J.; Robinson, W. H.; Fathman, C. G. Differential mTOR and ERK pathway utilization by effector $\mathrm{CD} 4 \mathrm{~T}$ cells suggests combinatorial drug therapy of arthritis. Clin. Immunol. 2012, 142, 127-138. 